\title{
Cidade à venda: reflexões éticas sobre o marketing urbano*
}

\author{
Fábio DuArte** \\ Sérgio Czajkowski Júnior***
}

SuMÁRIO: 1. Introdução; 2. Metodologia de pesquisa; 3. Marketing; 4. Marketing urbano (city marketing); 5. Os limites éticos; 6. Conclusões.

SUMMARY: 1. Introduction; 2. Research methodology; 3. Marketing; 4. City marketing; 5. The ethical limits; 6. Conclusions.

PALAVRAS-CHAVE: marketing urbano; gestão urbana; ética pública.

KEY WORDS: city marketing; urban management; public ethics.

A partir de uma exposição e discussão conceitual sobre marketing urbano, este artigo propõe uma reflexão dos limites éticos da incorporação das estratégias de marketing pelas cidades, que, a partir dos anos 1990, vêm adotando de forma explícita conceitos de marketing, tanto para a melhoria de sua imagem internamente, quanto, e principalmente, para potenciais investidores. Uma das razões para o emprego de estratégias de marketing urbano é posicionar a cidade perante a um mercado globalizado de fluxos de pessoas, investimentos e informações. Os críticos contrários à estratégia argumentam que isso transforma a cidade em mercadoria; os favoráveis, que é ferramenta inovadora para articulação entre agentes públicos e privados, objetivando a melhoria socioeconômica das cidades e conseqüente atendimento do interesse coletivo.

\footnotetext{
* Artigo recebido em dez. 2005 e aceito em jun. 2006.

** Arquiteto, urbanista, doutor em comunicações pela Universidade de São Paulo, professor do Mestrado em Gestão Urbana da Pontifícia Universidade Católica do Paraná (PPGTU/PUC-PR). Endereço: Rua Imaculada Conceição, 1155 - CEP 80215-901, Curitiba, PR, Brasil. E-mail: duarte.fabio@pucpr.br.

*** Graduado em direito pela Universidade Federal do Paraná, especialista em marketing pela PUC-PR, mestrando em Gestão Urbana pela PUC-PR. Endereço: Rua Imaculada Conceição, 1155 - CEP 80215-901, Curitiba, PR, Brasil. E-mail: sergiocza@yahoo.com.br.
} 


\section{City for sale: ethical reflections on urban marketing}

This article, through an exposition and conceptual discussion about city marketing, proposes a reflection on the ethical limits of incorporating marketing strategies to the cities. Since the nineties, cities have been adopting explicitly some marketing concepts so as to improve their image internally, for their citizens, and mainly externally, for potentials investors. One of the goals of city marketing strategies is to place the city in a privileged position in a globalized market of people, investments and information flows. This strategy's critics argue that it transforms the city into merchandise; those who are for it say that it is an innovative tool for articulating public and private agents, so as to improve the social-economic aspects of cities and consequently respond to the public interest.

\section{Introdução}

O processo de globalização, embora seja mais facilmente perceptível em termos econômicos (Baumann, 1996), não pode ser analisado dentro de uma visão sectária, sem que sejam estudados, paralelamente, os seus desdobramentos nos campos político, social e ético-cultural. Somente por meio dessa análise poderiam ser desvendados os reais motivos que fazem com que "vivamos num mundo confuso e confusamente percebido" (Santos, 2000:17).

Nesse contexto, onde Jameson (1996:29) vê a emergência de uma nova dominante cultural, há uma crescente competitividade que se espalha por diferentes esferas e escalas da vida em sociedade, em especial nos países de desenvolvimento tardio. Em tais regiões propaga-se a crença de que seu atraso somente poderia ser superado com a adoção de um ideário em que valores como a livre concorrência, o apreço ao trabalho e o mito do vencedor (self-made-man) deveriam ser estendidos a todos os níveis sociais. Entendida por esse aspecto, a globalização trouxe consigo uma nova percepção da realidade, em que não só as pessoas, como as empresas e até mesmo as cidades (Sánchez Garcia, 1999; Frúgoli Jr., 2001) e países deveriam dar o melhor de si, para atingir os seus objetivos numa escala mundial, uma vez que a lógica da efetividade do mundo da performance (Dupas, 2000:56-57), sob o prisma da valorização dos vencedores (Fonseca, 1999), seria algo plenamente aplicável a todas as esferas: locais, regionais e internacionais.

A cidade tornando-se agente em um contexto competitivo global é ressaltada por Rosabeth Kanter (2003:120) como uma possível forma de incremento urbano: 
O grande perigo à viabilidade de comunidades não é a globalização, mas uma volta ao isolacionismo e protecionismo. (...) Ironicamente, a melhor maneira de as comunidades preservarem seu controle local é tornarem-se mais competitivas globalmente.

Em visão oposta, Fernanda Sánchez Garcia (2001:32) critica dizendo que a sociedade capitalista contemporânea forja modelos de sucesso (como no caso das cidades vencedoras), que seriam baseados no conceito de boas práticas e na idéia de que as pessoas, as empresas e as cidades deveriam construir uma imagem vendável. Por isso, conceitos e estratégias de marketing, oriundos da iniciativa privada, adentram-se nas prefeituras e tornam-se estratégias públicas.

É diante deste quadro, em que "quase da noite para o dia, posicionamento tornou-se a palavra da moda entre os profissionais da propaganda e do marketing" (Ries e Ries, 2002:11), fazendo com que até mesmo os gestores comecem a se preocupar com a promoção de estratégias discursivas urbanas, que este artigo se propõe a analisar a viabilidade em se importar metodologias oriundas da iniciativa privada, em favor do desenvolvimento de políticas públicas de promoção da imagem das cidades.

\section{Metodologia de pesquisa}

Iniciamos apresentando algumas características do marketing contemporâneo, baseado em grande parte, segundo Tavares (2003), nas contribuições de Al Ries e Jack Trout (dentro da noção de posicionamento em termos de imagem), bem como de Michael Porter (em prol da valorização de um posicionamento, enquanto estratégia competitiva) e sua respectiva aplicabilidade no caso das urbes.

Na seqüência, fazemos uma análise mais crítica do marketing urbano, bem como quais seriam os seus limites no que tange à observação do preceito constitucional do primado do interesse coletivo.

Nossa intenção é discutir as limitações de tal metodologia, partindo da premissa de que enquanto a iniciativa privada é regida por princípios mais relacionados à lucratividade e à eficiência, voltando-se ao atendimento de necessidades específicas de certas parcelas da população, a pública deve sempre primar pelo bem-estar da coletividade.

\section{Marketing}

A história do marketing é recente (Longenecker, 1981; Kotler, 2000; Cooper, 2001), uma vez que o seu verdadeiro desenvolvimento teria se dado apenas a 
partir das décadas de 1960 e 1970, quando as empresas norte-americanas, conscientes do crescimento cada vez mais acentuado "das pressões sociais e empresariais" (Cooper, 2001:382), e percebendo as limitações do modelo fordista de produção (acentuadas pela recuperação européia e japonesa no período pós-II Guerra Mundial), sentiram-se impelidas a desenvolver uma metodologia que as tornasse mais dinâmicas em face das demais.

Mesmo assim, a atual percepção do marketing como "processo social e gerencial através do qual pessoas e grupos obtêm aquilo que necessitam e o que desejam através da criação, oferta e livre negociação de produtos e serviços de valor com outros" (Kotler, 2000:30) é algo que somente ganhou corpo a partir da década de 1980.

Somente a partir desse período se adotou uma "abordagem voltada ao consumidor" (Cooper, 2001:383), que, segundo Drucker (citado por Kotler, 2000), consistiria em tornar a venda supérflua, já que o grande mérito do profissional de marketing seria deixar "o cliente pronto para comprar" (Kotler, 2000:30).

Segundo Longenecker (1981:27), antes da preponderância do atual momento histórico, denominado Era do Marketing, a indústria teria passado por dois estágios anteriores, a Era da Produção, com o desenvolvimento do modelo fordista de produção, aliado às teorizações de Frederick W. Taylor e Henri Fayol, "se os produtos tivessem preços baixos o suficiente, eles seriam comprados" (citados por Cooper, 2001:383), e a Era das Vendas, em que as empresas "tentavam vender os produtos que haviam criado" (Cooper, 2001:383), pelo aprimoramento de suas técnicas de venda (Dearlove e Crainer, 1995:14).

O grande passo em prol da construção da atual percepção do marketing teria sido dado em 1972, quando Al Ries, conjuntamente com Jack Trout, publicou um artigo na "revista Advertising Age, intitulado 'Positioning era', que destacava a importância do conceito de posicionamento como a base do pensamento estratégico" (Tavares, 2003:125).

O conceito de posicionamento, cuja essência poderia ser definida, segundo Madia de Souza (1998), pela idéia de que seria mais importante, para uma empresa, se obter o share of mind do que o share of market, revolucionou o mercado da época. Pois, a partir de então, percebeu-se que seria muito mais proveitoso para todas as organizações desenvolver produtos dotados de algum diferencial competitivo marcante na mente de poucos consumidores (nicho de mercado) do que simplesmente comercializar os seus bens e/ou serviços pelo menor preço possível, tal como se fossem commodities, para as grandes massas.

Assim, o foco, anteriormente situado no produto, desloca-se para o comprador, fazendo inclusive com que as empresas deixassem de praticar somente políticas internas de aumento da produtividade e passassem também a enfocar 
o controle da qualidade, em prol da conquista efetiva dos seus consumidores (Juran, 1992; Grove, 1997).

As contribuições de Al Ries e Jack Trout foram aprimoradas por Michael Poter, para quem o sucesso de uma empresa estaria na conquista de uma posição "na qual a empresa possua uma condição tão diferenciada, que é bastante difícil copiá-la" (citado por Tavares, 2003:127), tornando o conceito de posicionamento imprescindível para a elaboração de qualquer estratégia de sucesso de marketing.

Cooper (2001:382) defende que a prova maior do sucesso do marketing como ciência que desenvolve uma imagem, uma percepção, um posicionamento, na mente dos seus consumidores é a de que, na atualidade, "as organizações que utilizam o marketing não se limitam a empresas comerciais", uma vez que as técnicas de marketing estão sendo paulatinamente incorporadas por outras instituições públicas, chegando a ser adotadas por alguns gestores urbanos origem do city marketing, ou marketing urbano.

\section{Marketing urbano (city marketing)}

Tomando-se como ponto de partida a constatação de que, nos dias de hoje, "os consumidores deparam-se com diversos tipos de produtos e serviços, fazendo suas escolhas com base em suas percepções do valor que estes os proporcionam" (Kotler, 2001:6), muitos gestores urbanos estão importando certas metodologias da iniciativa privada (notadamente aquelas que possuem maior relação com o marketing) com o objetivo de tornar as suas cidades dotadas de um maior valor aos olhos de seus moradores e especialmente dos investidores externos.

Ribeiro e Garcia (1996), Sánchez Garcia (1999, 2001), Pereira (2003), entre outros, a partir da análise das novas políticas públicas adotadas não só no Brasil, mas também em outros países do mundo, e particularmente relacionadas com a promoção das cidades na esfera local, regional e global, denominam tal processo de city marketing. Pereira (2003) defende que o city marketing passou a ser sistematizado a partir da década de 1980, adquirindo, posteriormente, um "conjunto mais largo de significados na Europa Ocidental" (Pereira, 2003:5), bem como na própria América Latina. Para Van Gent e Peelen (citados por Pereira, 2003:5), o city marketing é um termo que "passou a significar promoção ou, até mesmo, competitividade da cidade como um todo", sendo que tal atitude não se limitaria a um desejo de melhora do tecido urbano-arquitetônico da cidade; mas marcaria, na verdade, a adesão da cidade às novas tendências internacionais, que partiriam da premissa que a "qualidade do espaço urbano encontra-se vinculada ao aumento da competitividade" (Pereira, 2003:5). 
Cavalcanti e Neves (2004:1), partícipes do mesmo ponto de vista, caracterizam o city marketing como a "reorganização do espaço urbano a fim de garantir aos seus habitantes boa qualidade de vida e poder concorrer com outras cidades na atração de investimentos e atividades terciárias através dos meios de comunicação". Já Ribeiro e Garcia (1996, citado por Cavalcanti e Neves, 2004:1) acreditam que "o chamado city marketing provém do mecanismo institucional de promoção e venda da cidade como lugar onde se concretiza o espírito de inovação e de onde as novidades são irradiadas".

Segundo Sánchez Garcia (1999:1) a valorização do city marketing também seria fruto da atual conjuntura econômica mundial, na qual se desenharia uma situação cada vez mais instável para os centros urbanos, "seus modelos de desenvolvimento, suas funções e suas morfologias". Pois nesse cenário é que se perceberia um aumento contínuo nos níveis de competitividade entre os lugares e os próprios setores (áreas, bairros) distintos de uma mesma cidade, "com a valorização da dimensão local no contexto da globalização" (Sánchez Garcia, 1999:1), como também pela adoção do receituário (neo)liberal da livre concorrência, já que o capital cada vez mais especulativo (Santos, 2000:100) enxergaria até mesmo as cidades como locais de investimento, caso elas fossem capazes de gerar uma expectativa de ganhos (lucros) futuros.

Tomando-se como ponto de partida apenas os exemplos mais consagrados na literatura, percebe-se que as cidades de Barcelona (Sánchez Garcia, 1999), Curitiba (Sánchez Garcia, 2001), Belo Horizonte (Pereira, 2003) e Fortaleza (Ribeiro e Garcia, 1996) foram paradigmáticas nos anos 1990, sendo apresentadas como modelos de administração inteligente e criativa, graças à adoção mais ou menos extensiva de práticas de city marketing, aliadas a uma reestruturação do tecido urbano.

O que Sánchez Garcia (1999:2) salienta, contudo, é que o processo de valorização da imagem, inclusive no cenário internacional dessas cidades, foi acompanhado por uma "notável expansão dos departamentos e agências de comunicação e marketing dentro das respectivas estruturas administrativas locais". Ao mesmo tempo em que se verificou que a própria elaboração do planejamento estratégico urbano deixou de estar vinculada exclusivamente ao poder público, "sendo sua composição dirigida, sobretudo, por segmentos empresariais, a mídia local e grupos de pesquisa, apesar da presença articuladora de dirigentes de órgãos públicos" (Pereira, 2003:6).

Tal situação fez com que se passasse a questionar até que ponto a valorização da imagem dessas cidades seria fruto direto de um real aprimoramento nos padrões de vida de suas respectivas populações (em decorrência de um planejamento urbano mais eficiente) ou estaria respaldado no trabalho de uma equipe técnica qualificada (experts), que contaria com o apoio direto do 
empresariado e da mídia local, e cuja principal missão seria a de incrementar o processo de venda dessas cidades.

Sanchéz Garcia procura trazer à tona o fato de que, no atual arranjo de forças entre o poder público e a iniciativa privada, verifica-se que o primeiro não mais constrange o segundo em prol de investimentos, havendo, ao contrário, "uma clara confluência de interesses entre o governo da cidade e os setores empresariais" (Sánchez Garcia, 1999:5). Percebe-se, contudo, que a radicalização das práticas de city marketing teria feito com que vender a cidade (como se ela fosse um produto) tornar-se-ia tão ou mais importante do que realizar um planejamento urbano eficiente, realmente respaldado nas reais necessidades da população.

\section{Os limites éticos}

Mesmo tomando as considerações de Sanchéz Garcia (1999, 2001), Frúgoli Jr. (2001) e Pereira (2003), defendemos que não haveria nenhum mal ou irregularidade na mera utilização de práticas de city marketing por parte dos gestores urbanos, que somente passariam a existir quando aquelas visassem à obtenção de benefícios a grupos específicos de poder. Em certos casos, percebe-se que "muito embora as políticas de city marketing desenvolvam campanhas com aparente envolvimento de amplo espectro das populações locais" (Sánchez Garcia, 1999:1), o que realmente ocorreria seria uma deturpação da realidade.

Tal processo, muitas vezes justificado ante a necessidade de "aumentar a capacidade de atração do produto cidade" (Sánchez Garcia, 1999:5), faz com que processos comunicativos que mostram à exaustão pequenas e simbólicas cenas cotidianas (slices of life), aos poucos, ganhem total consistência na mente dos espectadores.

Pois, tal como Pierre Bourdieu defende, "o que há de mais terrível na comunicação é o inconsciente da comunicação" (citado por Ramonet, 1999:7), ocorrendo, no caso dos moradores das cidades, um lento e contínuo processo de sedimentação de pequenas imagens, que levam os receptores a uma falsa noção da totalidade. Visto que os moradores, bem como os demais espectadores, passam a acreditar que toda a cidade estaria se desenvolvendo, ou ainda, se beneficiando das referidas transformações, quando tal quadro seria no fundo falacioso e parcial, uma vez que até mesmo "o lançamento de cada novo produto urbanístico costuma ser minuciosamente planejado" (Sánchez Garcia, 1999:7), para que se tenha a noção de que toda a cidade estaria sendo beneficiada.

Tal estratégia, muito embora não seja uma mentira completa, não esconde a real situação da cidade, aliada ao fato de que "o controle da mídia e o domínio 
da televisão não produzem automaticamente o controle dos espíritos" (Ramonet, 1999:27) mas promovem, contudo, uma visão distorcida da realidade.

Tanto que para Sanchéz Garcia $(1999,2001)$ o uso indiscriminado do city marketing redundaria numa leitura incompleta dos fatos, uma vez que muitas das suas estratégias visariam apresentar a realidade de maneira deformada, a recompondo arbitrariamente. O que tornaria a construção social resultante de um processo de organização e seleção parcial da realidade, no qual os moradores seriam levados a crer, por exemplo, que não existiriam motivos consistentes para a reivindicação de um maior espaço de participação, já que a sua cidade estaria em boas mãos. Ou seja, "a assistência ao espetáculo cria uma ilusão de participação" (Sánchez Garcia, 1999:8) na população.

Diante de tais constatações, pleitear-se-ia que a utilização do city marketing fosse benéfica a todos os moradores, não sendo permitida, de forma alguma, uma nova concepção de cidadania, onde "o cidadão é confundido com consumidor e, por sua vez, a cidade com o mercado" (Sánchez Garcia, 1999:7), sob pena de estar ocorrendo um desvirtuamento não só do city marketing, como dos próprios objetivos centrais da administração pública que podem ser consubstancializados por meio da valorização do interesse coletivo.

Paralelamente, defende-se que não poderiam ser utilizadas técnicas de city marketing, pois, uma vez que as cidades na contemporaneidade tornaramse imensos quebra-cabeças, formados pelas diversas regiões constituintes das urbes (Rolnik, 2001:43), haveria a necessidade dos gestores criarem ícones modernos (produtos urbanos), a partir dos quais seria facilitada a coesão social.

Pois, neste caso, verificar-se-ia que tais ferramentas midiáticas ao invés de estarem colaborando para o desenvolvimento de toda a coletividade estariam sugerindo implicitamente "uma vida de classe média para todos os cidadãos" (Sánchez Garcia, 1999:7), que não só seria falaciosa, como também desestimularia o morador a pleitear uma maior participação nas decisões políticas, sob o argumento de que sua participação deveria ser limitada à condição de figurante (Sánchez Garcia, 1999:9) e não mais de ator político.

\section{Conclusões}

A principal questão colocada pelos críticos do marketing urbano é a transformação das cidades em mercadoria. Tal processo, levado às últimas conseqüências, faria com que seus moradores ficassem cada vez mais sedentos de novidades, e transformando os "espaços em pastiches, clichês superficiais de uma idéia de cidade” (Sánchez Garcia, 1999:7). 
Muito embora não haja mais dúvidas em se dizer que, hoje em dia, "o mercado domina a cidade" (Rolnik, 2001:29), haveria a necessidade dos gestores urbanos não se encantarem excessivamente por práticas oriundas da iniciativa privada, pois muito embora elas possam ser importadas para a administração pública, o seu uso de forma alguma pode interferir na premissa basilar de que o interesse coletivo deve sempre preponderar.

Pois, por mais que hoje em dia exista a crença na possibilidade de se construírem cidades-modelo, onde toda a população poderia usufruir as benesses de tal processo, "a cena clássica cotidiana das grandes massas se deslocando nos transportes coletivos superlotados ou no trânsito engarrafado são a expressão mais acabada desta limitação" (Rolnik, 2001). Advindo justamente daí a necessidade de limitar a transformação do espaço em um mero cenário, em uma mera imagem, "onde tudo é objeto de consumo estético e contemplativo" (Garcia, 1999:7), pois nesse caso estar-se-ia incentivando a construção de falsos simulacros (Dupas, 2000:57), em que não mais a realidade e sim o espetáculo seria a prioridade.

\section{Referências bibliográficas}

BAUMANN, R. (Org.). O Brasil e a economia global. Rio de Janeiro: Campus, 1996.

CAVALCANTI E.; NEVES M. F. Curitiba viável ao turismo. 2004. Disponível em: <www.fotoserumos.com/curitibaviavel16.htm>. Acesso em: 10 abr. 2005.

COOPER. C. Turismo, princípios e práticas. Porto Alegre: Bookman, 2001.

DEARLOVE, D.; CRAINER, Stuart. O livro definitivo das marcas. São Paulo: Makron Books, 1995.

DUPAS, G. Ética e poder na sociedade da informação. São Paulo: Unesp, 2000.

FONSECA, R. M. Walter Benjamin, a temporalidade e o direito. In: MUSSE, R. et al. A escola de Frankfurt no direito. Curitiba: Edibej, 1999. p. 75-86.

FRÚGOLI JR., H. A questão da centralidade em São Paulo: o papel das associações de caráter empresarial. Revista de Sociologia Política, Curitiba, n. 16, p. 51-66, jun. 2001.

GROVE, A. Administração de alta performance: transformando subordinados e colaboradores em uma equipe altamente produtiva. São Paulo: Futura, 1997.

JAMESON, F. Pós-modernismo a lógica cultural do capitalismo tardio. São Paulo: Ática, 1996. 
JURAN, J. M. A qualidade desde o projeto. São Paulo: Pioneira, 1992.

KANTER, Rosabeth Moss. Thriving locally in the global economy. Harvard Business Review, p. 119-127, Aug. 2003.

KOTLER, P. Administração de marketing. São Paulo: Prentice Hall, 2000.

LONGENECKER, J. G. Introdução à administração. São Paulo: Atlas, 1981.

MADIA DE SOUZA, F. A. Marketing pleno. Tudo o que você precisa saber para praticar um marketing da maior qualidade e de última geração. São Paulo: Makron Books, 1999.

PEREIRA, V. Planejamento urbano e turismo cultural em Belo Horizonte, Brasil: espetacularização da cultura e a produção social das imagens urbanas. In: CONGRESSO VIRTUAL DE TURISMO, 2., 2003. Anais... 2003.

RAMONET, I. A tirania da comunicação. Petrópolis: Vozes, 1999.

RIBEIRO, J. A.; TAVARES, N. A revolução ecológica. Curitiba: Lagarto, 1992.

RIES, A.; TROUT, J. Posicionamento: a batalha pela sua mente. São Paulo: Pioneira, 1996.

; RIES, L. A queda da propaganda — da mídia paga à mídia espontânea. Rio de Janeiro: Campus, 2002.

ROLNIK, R. O que é cidade. São Paulo: Brasiliense, 2001.

SÁNCHEZ GARCIA, F. Buscando um lugar ao sol para as cidades: o papel das atuais políticas de promoção urbana. In: Revista Paranaense de Geografia, Associação dos Geógrafos Brasileiros, n. 4, 1999. Disponível em: <www.agbcuritiba.hpg.ig.com.br/Revistas/Rpg3/ 4fernanda.htm $>$.

. A reinvenção das cidades na virada de século. Agentes, estratégias e escalas de ação política. Revista de Sociologia Política, Curitiba, n. 16, p. 31-49, jun. 2001.

RIBEIRO, J.; SANCHES GARCIA, F. Citymarketing e Curitiba: cultura e comunicação na construção da imagem urbana. São Paulo: UFSCAR, 1996.

SANTOS, M. Por uma outra globalização: do pensamento único à consciência universal. São Paulo: Record, 2000.

TAVARES, F. Marketing-mind brand positioning. Revista Comum, Rio de Janeiro, Faculdades Integradas Hélio Alonso (Facha), v. 7. n. 20, p. 125-149, jan./jun. 2003.

THOMPSON, J. A mídia e a modernidade: uma teoria social da mídia. Rio de Janeiro: Vozes, 1998. 